\title{
Correction to: Glycemic control and healthcare utilization following pregnancy among women with pre-existing diabetes in Navajo Nation
}

Julius Ho ${ }^{1}$, Karen Bachman-Carter ${ }^{2}$, Shelley Thorkelson ${ }^{2}$, Kristi Anderson ${ }^{2}$, Jennifer Jaggi ${ }^{3}$, Chris Brown ${ }^{4,5}$, Adrianne Katrina Nelson ${ }^{6}$, Cameron Curley ${ }^{4,5}$, Caroline King ${ }^{4,5}$, Sid Atwood ${ }^{4}$ and Sonya Shin ${ }^{4,5,6^{*}}$

\section{Correction to: BMC Health Serv Res (2018) 18:629 https://doi.org/10.1186/s12913-018-3434-x}

In the original publication of this article [1], an author's name needs to be revised from Katrina Nelson to Adrianne Katrina Nelson, and this author's affiliation address should be "641 Huntington Ave., Boston, MA 02115". The origial article has been corrected for the author's name.

\begin{abstract}
Author details
'Department of Medicine, Johns Hopkins School of Medicine, 1800 Orleans St, Baltimore, MD 21298, USA. ${ }^{2}$ Northern Navajo Medical Center, Indian Health Service, Shiprock, NM, USA. ${ }^{3}$ Gallup Indian Medical Center, Indian Health Service, Gallup, NM, USA. ${ }^{4}$ Division of Global Health Equity, Brigham and Women's Hospital, 210 East Aztec Avenue, Gallup, NM 87301, USA. ${ }^{5}$ Community Outreach and Patient Empowerment, 210 East Aztec Avenue, Gallup, NM 87301, USA. 'Department of Global Health and Social Medicine, Harvard Medical School, 641 Huntington Ave., Boston, MA 02115, USA.
\end{abstract}

Published online: 22 October 2019

\section{Reference}

1. Ho et al. Glycemic control and healthcare utilization following pregnancy among women with pre-existing diabetes in Navajo Nation. BMC Health Services Research (2018) 18:629.

\footnotetext{
* Correspondence: sshin@partners.org

${ }^{4}$ Division of Global Health Equity, Brigham and Women's Hospital, 210 East Aztec Avenue, Gallup, NM 87301, USA

${ }^{5}$ Community Outreach and Patient Empowerment, 210 East Aztec Avenue, Gallup, NM 87301, USA

Full list of author information is available at the end of the article
}

(c) The Author(s). 2019 Open Access This article is distributed under the terms of the Creative Commons Attribution 4.0 International License (http://creativecommons.org/licenses/by/4.0/), which permits unrestricted use, distribution, and reproduction in any medium, provided you give appropriate credit to the original author(s) and the source, provide a link to the Creative Commons license, and indicate if changes were made. The Creative Commons Public Domain Dedication waiver (http://creativecommons.org/publicdomain/zero/1.0/) applies to the data made available in this article, unless otherwise stated. 